review of the safety of SSRIs. No members of the expert working group have financial interests in any of the companies that hold marketing authorisations for SSRIs. The MHRA funded the study and professional staff at the MHRA, including JM and LW, have been acting as secretariat to or observers on the expert working group's review. Neither JM nor LW have any personal financial interests in any drug product. DG, JC, and DA are members of the MHRA's expert working group on the safety of SSRIs, and DA is a member of the Committee on Safety of Medicines. They act as independent advisers, receiving travel expenses and a small fee for meeting attendance and reading materials in preparation for the meeting. DA has spoken on the methodology of adverse drugs reactions in HIV at a scientific meeting attended by several pharmaceutical companies and sponsored by GlaxoSmithKline (GSK). A honorarium was paid to her department. SE has no personal interests to declare. His department receives funding from many pharmaceutical companies, including GSK, but mainly for methodological research. SE has no direct involvement in any of this. The General Practice Research Database Division receives funding for services, including the conduct of commissioned research, from a wide range of public sector bodies and the pharmaceutical industry. CM and SR have no competing interests to declare.
Ethical approval: General Practice Research Database Scientific and Ethical Advisory Group.

Gunnell D, Ashby D. Antidepressants and suicide: what is the balance of benefit and harm. BMJ 2004;329:34-8.

2 Anonymous. SSRI and venlafaxine use in children. Curr Probl Pharmacovigilance 2003;29:4.

3 Whittington CJ, Kendall T, Fonagy P, Cottrell D, Cotgrove A, Boddington E. Selective serotonin reuptake inhibitors in childhood depression: systematic review of published versus unpublished data. Lancet systematic review of published versus unpublished data. Lancet 2004;363:1341-5.

4 Jick SS, Dean AD, Jick H. Antidepressants and suicide. BMJ 1995;310:215-8.

5 Jick H, Kaye J, Jick SS. Antidepressants and the risk of suicidal behaviors. JAMA 2004;292:338-43.

6 Hawton K, Harriss L, Hall S, Simkin S, Bale E, Bond A. Deliberate self-harm in Oxford 1990-2000: a time of change in patient characteristics. Psychol Med 2003;33:987-95.

7 Gunnell D, Frankel S. Prevention of suicide: aspirations and evidence. BMJ 1994;308:1227-33.

8 Hawton K, Fagg J, Simkin S, Bale E, Bond A. Trends in deliberate self-harm in Oxford, 1985-1995. Implications for clinical services and the prevention of suicide. Br J Psychiatry 1997;171:556-60.

9 National Statistics Online. Trends in suicide by method in England and Wales, 1979 to 2001. www.statistics.gov.uk/downloads/theme_health/ HSQ20.pdf (accessed 24 Jan 2005):7-18.

(Accepted 11 January 2005)

\title{
Subfecundity and neonatal mortality: longitudinal study within the Danish national birth cohort
}

\author{
Olga Basso, Jørn Olsen
}

Treatment for infertility correlates with adverse outcomes in pregnancy, especially in singleton deliveries. ${ }^{1} \mathrm{~A}$ long time to pregnancy (subfecundity) also correlates with adverse outcomes, ${ }^{2-4}$ but few studies evaluating treatment take subfecundity into consideration. We explored the association between time to pregnancy and neonatal death in the Danish national birth cohort.

\section{Participants, methods, and results}

We identified 27624 firstborn singleton babies, born alive from the 24th week of gestation between March 1998 and December 2001, whose mothers were enrolled in the Danish national birth cohort. ${ }^{45}$ Mothers had been interviewed during pregnancy ( $50 \%$ by the 16 th completed week and $95 \%$ by the 25 th) and asked about pregnancy planning and other factors.

Women who reported having planned or partly planned their pregnancy were asked how long it had taken them to conceive. If the answer was six months or longer, they were further asked whether they had received infertility treatment. We excluded 402 women reporting infertility treatment after less than one year of trying and 11 women with missing data on smoking. We analysed 27329 births (with 66 deaths within 28 days of life $(0.24 \%))$. Age at death was recorded in the Danish birth registry.

We grouped women into five categories: up to two months of waiting time (reference); 3-12 months; $>12$ months, no infertility treatment; $>12$ months, treatment reported; and non-planners (including part planners). We examined the association between these categories and neonatal death through logistic regression, adjusting for mother's age, body mass index, smoking, and social class, the latter derived from the mother's job title. ${ }^{4}$

The risk of neonatal death increased with increasing time to pregnancy (table). Death between the 29th and the 365th day of life was not related to time to pregnancy (data not shown).

This article was posted on bmj.com on 4 February 2005: http://bmj.com/ cgi/doi/10.1136/bmj.38336.616806.8F
Danish

Epidemiology Science Centre Department of Epidemiology and Social Medicine, University of Århus, Århus, Denmark (DK8000)

Olga Basso research associate professor Jørn Olsen professor

Correspondence to: O Basso bassoo2@ niehs.nih.gov

BMJ 2005;330:393-4

\begin{tabular}{|c|c|c|c|}
\hline Time to pregnancy or treatment & Deaths/births (per 1000) & Crude odds ratio $(95 \% \mathrm{CI})$ & Adjusted odds ratio* $(95 \% \mathrm{CI})$ \\
\hline$<3$ months & 13/8361 (1.55) & 1.00 & 1.00 \\
\hline 3-12 months & $22 / 7944(2.77)$ & 1.78 (0.90 to 3.54$)$ & 1.76 (0.89 to 3.50$)$ \\
\hline$>12$ months & $18 / 4142(4.35)$ & 2.80 (1.37 to 5.73$)$ & 2.82 (1.35 to 5.90$)$ \\
\hline No treatment reported & $11 / 2104(5.23)$ & 3.38 (1.51 to 7.54 ) & 3.32 (1.47 to 7.53$)$ \\
\hline Treatment reported & $7 / 2038$ (3.03) & 2.21 (0.88 to 5.55$)$ & 2.32 (0.86 to 5.80$)$ \\
\hline Unplanned or partly planned & 13/6882 (1.89) & 1.22 (0.56 to 2.62$)$ & 1.14 (0.52 to 2.49$)$ \\
\hline
\end{tabular}

*Adjusted for mother's age at delivery ( $<26$ years, $26-30,31-35, \geq 36$ ), smoking from conception to time of interview (no/yes), pre-pregnancy body mass index $(<20$, 20-24.9, 25-29.9, $\geq 30$, missing), and social class (low, middle, high, missing). All covariates except age were self reported. When social class or body mass index were missing $(4.8 \%)$, we included a separate category in the variable. 


\section{Comment}

Mothers waiting for longer than one year to conceive their first child gave birth to babies with a higher risk of neonatal death compared with children conceived sooner. We restricted the analysis to primiparae $(73.5 \%$ of whom reported no previous pregnancies) because death of a previous baby may influence both the decision to conceive again and its outcome.

Infertility treatment was self reported and was only asked of women taking longer than six months to conceive, but there was little difference in risk between treated and untreated, although the causes of death may differ between the two groups.

Only about $35 \%$ of eligible women participated in the cohort, ${ }^{5}$ and this could cause bias if participants with a long time to pregnancy were at a different level of risk compared to the non-participants. Furthermore, we could not distinguish the length of infertility beyond one year, which limits our ability to identify a dose-response, if it exists.

We collected information on time to pregnancy and confounders before delivery, reducing the potential for other types of bias. The mother's job title may be a poor proxy for social class, but the adjustment appeared to have little effect on our estimates.

A long time to pregnancy per se is not commonly considered a marker of increased risk, and untreated women with a history of infertility may seek (or receive) inadequate prenatal care.

Even though neonatal death was a rare event in this population, it is a serious outcome and any potential risk marker should be considered. Our finding needs, however, to be corroborated elsewhere before it can be stated that a long time to pregnancy increases the risk of neonatal death.

If infertility itself is associated with adverse outcomes, an appropriate comparison group should be used when assessing effect of infertility treatment on pregnancy outcomes, lest adverse effects of treatment be overestimated.

\section{What is already known on this topic}

Infertility treatment is correlated to adverse pregnancy outcomes, and evidence indicates that subfecundity per se is also associated with adverse pregnancy outcomes

\section{What this study adds}

Subfecundity may be associated with an increased risk of neonatal death and should be included as a risk indicator in neonatal care

Contributiors: $\mathrm{OB}$ and $\mathrm{JO}$ had the idea for this study and formulated the hypothesis to be tested. OB analysed the data and both authors contributed to the interpretation of the findings. OB drafted the manuscript, and JO provided critical comments. JO is guarantor.

Funding: OB had a grant from the Danish Medical Research Council (No 22-00-0008). The Danish Epidemiology Science Centre was established by a grant from the Danish National Research Foundation. The Danish National Birth Cohort is funded by the Danish National Research Foundation, the Pharmacy Foundation, the Egmont Foundation, the March of Dimes Birth Defects Foundation, the Augustinus Foundation, and the Health Foundation.

Competing interests: None declared.

Ethical approval: National Scientific Ethics Committee.

1 Helmerhorst FM, Perquin DA, Donker D, Keirse MJ. Perinatal outcome of singletons and twins after assisted conception: a systematic review of controlled studies. BMJ 2004:328:261.

2 Olivennes F, Rufat P, Andre B, Pourade A, Quiros MC, Frydman R. The increased risk of complication observed in singleton pregnancies resulting from in-vitro fertilization (IVF) does not seem to be related to the IVF ing from in-vitro fertilization (IVF) does not

3 Henriksen TB, Baird DD, Olsen J, Hedegaard M, Secher NJ, Wilcox AJ. Time to pregnancy and preterm delivery. Obstet Gynecol 1997;89:594-9.

4 Basso O, Baird DD. Infertility and preterm delivery, birthweight, and Caesarean section: a study within the Danish national birth cohort. Hum Reprod 2003;18:2478-84

5 Olsen J, Melbye M, Olsen SF, Sorensen TI, Aaby P, Andersen AM, et al. The Danish national birth cohort: its background, structure and aim. Scand J Public Health 2001;29:300-7.

(Accepted 1 December 2004)

doi $10.1136 /$ bmj. $38336.616806 .8 \mathrm{~F}$

\section{Predicting the risk of repetition after self harm: cohort study}

Navneet Kapur, Jayne Cooper, Cathryn Rodway, Joanne Kelly, Else Guthrie, Kevin Mackway-Jones

Centre for Suicide Prevention,

Department of

Psychiatry and

Behavioural

Sciences, University

of Manchester,

Manchester

M13 9PL

Navneet Kapur

senior lecturer

Jayne Cooper

research fellow

Cathryn Rodway

research assistant

Joanne Kelly

research assistant

continued over

BMJ 2005;330:394-5
About one in six people repeat self harm within a year of an episode. ${ }^{1}$ Identifying people who are at risk of repetition is a key objective of assessment. ${ }^{2}$ We investigated the predictive value of risk assessments after an episode of self harm and compared assessments made by emergency department staff with those made by psychiatric staff.

\section{Participants, methods, and results}

Four hospitals provide emergency care in the cities of Manchester and Salford. As part of the Manchester and Salford self harm project (MASSH) we collected data on all people aged at least 16 who presented with self harm in 1997-2001. ${ }^{3}$ Doctors in the emergency department and, for those patients who received a psychiatric assess- ment, mental health staff completed comprehensive assessment forms (which included demographic items as well as details of the self harm episode, past history, and current mental state). The assessor was also asked for a global clinical assessment of the risk of repetition of self harm (low, moderate, or high). We used the MASSH database to determine whether people repeated self harm within 12 months of their first presentation. We calculated sensitivity, specificity, and positive predictive value for emergency department and specialist mental health risk assessments.

Overall, 7612 individuals presented with self harm (10 173 episodes). Emergency department staff were

This article was posted on bmj.com on 26 January 2005: http: bmj.com/ cgi/doi/10.1136/bmj.38337.584225.82 